\title{
Rekam Medis/Kesehatan Elektronik (RMKE): Integrasi Sistem Kesehatan
}

\author{
T. Sintak Gunawan', Gilbert Mayer Christianto \\ ${ }^{\mathrm{I}}$ Centre of Ethics, Universitas Katholik Atma Jaya
}

\author{
Kata Kunci \\ Teknologi informasi, rekam medis \\ elektronik, rekam kesehatan elektronik, \\ sistem kesehatan \\ Korespondensi \\ sintak.gunawan@atmajaya.ac.id \\ Publikasi \\ (C) $2020 \mathrm{JEKI} /$ ilmiah.id \\ DOI \\ I0.26880/jeki.v4it.43 \\ Tanggal masuk: 24 November 2019 \\ Tanggal ditelaah: I2 Januari 2020 \\ Tanggal diterima: 10 Februari 2020 \\ Tanggal publikasi: 24 Februari 2020
}

\begin{abstract}
Abstrak Integrasi teknologi dan informasi dengan berbagai sistem di dunia menghasilkan banyak inovasi dan kemajuan. Salah satu hasil penerapan kemajuan teknologi dan informasi dalam sistem kesehatan adalah berkembangannya rekam medis/kesehatan elektronik. Rekam medis/kesehatan elektronik sudah banyak digunakan terutama di negara-negara maju dengan macam-macam bentuknya. Di Indonesia, telah mulai dicoba untuk menerapkan sistem rekam medis/kesehatan elektronik dalam praktik. Akan tetapi belum semua penyedia layanan kesehatan sudah menerapkan sistem ini. Berikut akan dibahas lebih dalam mengenai rekam medis/kesehatan elektronik, beserta langkahlangkah penerapannya, dan problematika yang mungkin dihadapi.
\end{abstract}

\begin{abstract}
The integration of information technology with various systems in the world produces a lot of innovation and progress. One result of the application of technological advances in the health system is the development of electronic medical/health record. Various electronic medical/health records have been widely used, especially in developed countries. In Indonesia, attempts have already been made to implement electronic medical/health record system in practice. However, not all healthcare providers have implemented this system. This paper will discuss various aspects regarding electronic medical/ health records, including the steps to implement them and problems that may be encountered in the process.
\end{abstract}

Sistem Teknologi Informasi dan Komunikasi (TIK) sudah menjadi bagian yang integral dalam berbagai aspek kehidupan, termasuk dalam pelayanan kesehatan. Rekam Medis/Kesehatan Elektronik (RMKE) merupakan salah satu bentuk penerapan TIK dalam sistem pelayanan kesehatan melalui komputerisasi data pasien. RMKE mencakup Rekam Medis Elektronik (Electronic Medical Record) (EMR), Rekam Kesehatan Elektronik (Electronic Health Record), dan Rekam Kesehatan Pribadi (Personal Health Record). ${ }^{1}$

Rekam medis elektronik (RME) adalah versi digital dari rekam medis konvensional (berupa kertas) yang biasa digunakan di fasilitas kesehatan. RME berisi catatan dan informasi yang dikumpulkan oleh dan untuk dokter di fasilitas layanan kesehatan tersebut, yang digunakan untuktujuan diagnosis dan perawatan kesehatan pasien. RME memungkinkan penyedia layanan untuk melacak data pasien dari waktu ke waktu, identifikasi pasien untuk kunjungan pencegahan dan skrining, memantau pasien, dan meningkatkan kualitas perawatan kesehatan. ${ }^{1}$ Bukan hanya itu, dari segi biaya RME lebih efisien karena tidak mengeluarkan biaya untuk mencetak status dan tidak membutuhkan ruangan/tempat untuk penyimpanan.

Rekam kesehatan elektronik (RKE) dibuat lebih lengkap daripada data klinis standar yang dikumpulkan dalam RME di fasilitas kesehatan dan memberikan pandangan yang lebih luas tentang perawatan pasien. RKE berisi semua perawatan dan pemeriksaan yang pernah pasien jalani, misalnya kunjungan ke klinik layanan primer, klinik spesialis, rumah sakit, atau laboratorium klinis. RKE memungkinkan pertukaran informasi yang terintegrasi antara penyedia layanan kesehatan sehingga tenaga 
kesehatan yang akan memeriksa pasien mendapatkan gambaran yang komprehensif mengenai kondisi pasien yang ditanganinya. ${ }^{1}$

Rekam kesehatan pribadi (RKP) berisi jenis informasi yang serupa dengan RKE - diagnosis, obat-obatan, imunisasi, riwayat medis keluarga, dan informasi kontak penyedia - tetapi dibuat sedemikian rupa sehingga informasi tersebut dapat diatur untuk diakses dan dikelola oleh pasien. Pasien dapat menggunakan RKP untuk memelihara dan mengelola informasi kesehatan mereka di lingkungan pribadi secara aman dan rahasia. RKP dapat mencakup informasi dari berbagai sumber termasuk dokter, fasilitas kesehatan, perangkat pemantauan rumah, dan pasien sendiri. ${ }^{1}$

\section{Problematika RMKE di Dunia}

Rekam medis konvensional mempunyai banyak keterbatasan, diantaranya dari segi biaya untuk mencetak rekam medis dan penyimpanan rekam medis yang membutuhkan ruangan/ tempat khusus. Dari segi waktu, rekam medis konvensional kurang efisien karena dibutuhkan waktu untuk mencari dan mengambil rekam medis. Dari segi kesinambungan informasi, data klinis dalam rekam medis konvensional bisa terputus karena lama penyimpanan rekam medis konvesional mempunyai waktu terbatas tergantung kebijakan pelayanan kesehatan.

RMKE sudah lama diterapkan oleh banyak negara. Di Tiongkok, RMKE mulai dikembangkan dari tahun 1997 dipromotori oleh rumah sakit militer People's Liberation Army General Hospital (PLAGH). ${ }^{2}$ Pada tahun 2005, National Health System (NHS) di Inggris membuat keputusan untuk menerapkan sistem catatan kesehatan elektronik di setiap jejaring NHS Trusts. ${ }^{3}$ Negara Thailand sudah mulai melakukan komputerisasi dalam pengelolaan data pasien sejak tahun $2008 .^{4}$

Sistem pelayanan kesehatan elektronik dibangun dengan fungsi utama untuk melacak kunjungan pasien, riwayat medis, perawatan, dan resep obat. Saat ini, RMKE juga dikembangkan untuk mendukung fungsi administrasi dan pembayaran. Dengan sistem RMKE yang baik, diharapkan layanan kesehatan yang diberikan akan semakin baik dan aman untuk pasien dan masyarakat. $^{5}$

Namun, dalam kondisi saat ini, RMKE dapat menjadi tidak efisien dan sulit digunakan. Dari segi teknis, tantangan terbesar yang dihadapi adalah dari segi pendanaan. Masalah lain yang ditemukan adalah dari segi sumber daya, kurangnya profesional IT (Information Technology) yang terampil, diperlukan untuk mengintegrasikan data klinis pasien menjadi data digital RMKE. Tenaga kesehatan (terutama yang senior) juga tidak semangat untuk belajar menggunakan RMKE dalam praktik mereka. ${ }^{4}$

Penelitian lain menunjukkan bahwa dokter sekarang mencurahkan lebih banyak waktu untuk melakukan entry data daripada kontak/ komunikasi dengan pasien. Sebuah penelitian terhadap dokter yang menggunakan RMKE di unit gawat darurat menunjukkan bahwa dokter menghabiskan rata-rata $43 \%$ dari waktu mereka untuk entri data dan hanya $28 \%$ dari waktu mereka pada kontak pasien langsung. Dalam membuat keputusan, klinisi banyak mengabaikan pemeriksaan fisik, melakukan analisa pertimbangan klinis, dan lebih mengandalkan hasil catatan elektronik. Hal ini bisa membahayakan pasien karena kondisi tubuh manusia yang sangat dinamis dan bisa berubah dengan cepat. ${ }^{4}$

Pelanggaran kerahasiaan informasi medis tidak hanya dapat terjadi dengan catatan medis kertas (konvensional). Risiko pelanggaran kerahasiaan pada sistem RMKE dapat pula terjadi, bahkan lebih cepat dan luas. Akibatnya, fasilitas layan kesehatan harus waspada dalam mencegah akses yang tidak sah ke informasi pasien agar kerahasiaan data pasien terjaga. Hal ini mencakup ancaman dari pihak internal, dari manajemen, kata sandi yang buruk, rekan kerja yang tidak puas atau tidak loyal, dan langkahlangkah keamanan fisik yang transparan, serta ancaman eksternal, seperti pencurian perangkat elektronik yang mengandung informasi kesehatan. $^{2}$

\section{Problematika RMKE di Indonesia}

Di Indonesia, RMKE sudah mulai digunakan sejak akhir tahun 2000-an. Penggunaan teknologi dalam sistem pelayanan kesehatan di Indonesia awalnya terbatas untuk 
pencatatan data pasien. Namun, dengan perkembangan era sistem teknologi informasi, RMKE mulai digunakan dalam sistem rujukan berjenjang dan sistem pembayaran. Selain itu, RMKE juga digunakan dalam komunikasi dan pertukaran informasi antar fasilitas kesehatan, seperti di Jawa Tengah dimana setiap puskesmas dapat mengakses rekam medis elektronik yang terintegrasi sehingga dapat melacak riwayat pasien yang datang berobat. ${ }^{6}$

Namun, dalam sistem RMKE saat ini belum terjadi integrasi sepenuhnya antara data kesehatan pasien yang sekarang dengan riwayat kesehatan pasien yang terdahulu. Sistem ini membantu dalam perawatan pasien untuk kondisi akut/sekarang, tetapi untuk pasien dengan penyakit kronis atau penyakit kongenital, maka riwayat kesehatan pasien sebelumnya sangat krusial dalam menentukan rencana pengobatan pasien yang holistik dan berkesinambungan. Tidak jarang pasien harus menjalani berbagai pemeriksaan dari awal kembali karena ketidaktersediaan data kesehatan dahulu. RMKE seperti ini belum memenuhi potensi yang seharusnya bisa dicapai, yaitu peningkatan kualitas, peningkatan efisiensi, pengurangan biaya, dan penelitian.

\section{Langkah-langkah Pembuatan Sistem RMKE}

Belum semua rumah sakit di Indonesia menggunakan sistem RMKE. Perancangan dan penerapan yang terstruktur, menyeluruh, dan dilakukan secara hati-hati adalah kunci dalam merancang RMKE.

Lima hal yang harus diperhatikan terkait dengan pembuatan dan penerapan rekam medis elektronik adalah sebagai berikut:

1. Hubungan dokter-pasien

RMKE bertujuan untuk meningkatkan mutu layanan kesehatan. Klinisi harus mampu menggunakan RMKE sedemikian rupa sehingga tidak mengganggu interaksi dengan pasien yang dapat menyebabkan gangguan pelayanan bahkan keselamatan pasien, serta dibutuhkan kerja yang sistematis dan terintegrasi.

2. Privasi, rahasia, dan keamanan

Prinsip dasar rekam medis haruslah bersifat menjaga privasi, rahasia, dan aman (privacy, confidentiality, and security) baik dalam bentuk kertas maupun dalam bentuk elektronik. Oleh sebab itu, rekam medis harus dirancang sedemikian rupa sehingga ketiga aspek ini senantiasa terjamin. Seperti halnya rekam medis konvensional, hanya pihak berwenang saja yang boleh „masuk“ dan menggunakannya. Pasien perlu pula mengetahui dan memahami sistem RMKE. Untuk itu, perlu penjelasan yang memadai tentang sistem ini sehingga disetujui oleh pasien untuk dilaksanakan bersama-sama. Persetujuan ini dapat dilakukan secara lisan maupun tertulis, tergantung kebutuhan. Pihak penyedia layanan kesehatan perlu membuat pedoman teknis pelaksanaan untuk menjamin terjaganya keamanan, kerahasiaan, dan privasi RMKE.

3. Budaya penerapan RMKE

Perlu dipertimbangkan apakah para pihak yang terkait dapat beradaptasi dengan cara kerja RMKE karena adanya isu generation gap dan gagap teknologi. Dalam proses pendidikan sebelumnya, tenaga medis telah terbiasa menggunakan rekam medis kertas. Jika terjadi perubahan, yaitu penerapan RMKE, "budaya" baru ini perlu dipahami dan diterima oleh seluruh pihak yang terkait dengan penggunaan RMKE tersebut. Mungkin perlu jangka waktu tertentu untuk pelatihan dan penyesuaian budaya.

4. Keselamatan pasien

Perlu dipertimbangkan apakah penggunaan RMKE akan meningkatkan keselamatan pasien atau malah mengganggu dalam tindakan menyelamatkan pasien. Oleh sebab itu, perlu kepastian bahwa pihak yang terlibat dalam menggunakan RMKE, terutama dokter dan perawat, telah terampil menggunakannya.

5. Penggunaan RMKE untuk kepentingan lain Selain untuk pencatatan, RMKE juga bisa digunakan untuk kepentingan lain seperti pendidikan, penelitian, dan peradilan. Untuk kepentingan lain ini perlu dibuat peraturan khusus terkait dengan penggunaan RMKE. 
Langkah pertama yang diperlukan dalam pembuatan RMKE adalah mencari vendor untuk merancang sistem pelayanan kesehatan online. Banyak data-data medis yang perlu diolah mulai dari hasil anamnesis, pemeriksaan fisik, sampai data penunjang seperti pemeriksaan laboratorium dan radiologis. Kondisi tubuh manusia sangat kompleks dan berfluktuatif sehingga tidak jarang dibutuhkan pemantauan yang ketat dan berkesinambungan. Data yang diperoleh harus dapat diteliti, dipastikan kebenarannya, dan disimpan sebagaimana mestinya. Tidak semua vendor dapat menjembatani jarak antara bidang medis dan teknologi. Vendor yang kompeten dan berpengalaman dalam membuat sistem elektronik untuk bidang kesehatan terbatas. Untuk itu dibutuhkan kolaborasi antara sektor kesehatan dan sektor teknologi dalam merancang RMKE.

Saat ini, kebijakan dan peraturan yang terkait tentang RMKE masih terbatas. Kebutuhan tiap fasilitas layanan kesehatan berbeda-beda dan yang paling mengetahuinya adalah dari fasilitas layanan kesehatan itu sendiri. Namun, mereka membutuhkan suatu pedoman untuk bekerjasama dengan vendor untuk memulai pembuatan RMKE. Disini pemerintah bisa berperan dalam membuat pedoman dan anjuran dalam proses pembuatan RMKE tersebut.

Langkah kedua adalah kerjasama penyedia layanan kesehatan dengan vendor. Perbedaan persepsi bentuk/sistem RMKE antara penyedia layanan kesehatan dengan vendor sering kali terjadi. Oleh sebab itu, perlu penyetaraan atau persamaan persepsi antara kedua belah pihak melalui kerjasama yang baik. Hal ini membutuhkan cukup banyak waktu dan tenaga.

Rekam medis adalah privasi pasien, sehingga perlu dijaga agar tidak terjadi penyalahgunaan. Setiap pihak yang terlibat dalam pembuatan sistem RMKE ini perlu mengetahui peran dan kewenangan masingmasing pihak. Vendor perlu mengetahui dengan jelas berdasarkan UU kesehatan setiap orang yang terlibat dan menggunakan rekam medis berada dalam sumpah untuk menjaga kerahasiaan pasien layaknya dokter. Hal ini perlu dimasukkan dalam sistem RMKE. ${ }^{8}$

Langkah ketiga adalah implementasi RMKE. Orang-orang yang bekerja di fasilitasi layanan kesehatan berasal dari berbagai latar belakang yang berbeda-beda dan lintas generasi. Masing-masing mempunyai kemampuan untuk menangkap pembelajaran yang berbeda, terutama yang terkait dengan teknologi informasi. Maka perlu diadakan pelatihan yang terstruktur dan sistematis untuk mengubah pola pikir dan budaya dari pencatatan rekam medis konvensional menjadi pencatatan rekam medis digital.

Dalam masa pelatihan dan penyesuaian ini, pelayanan penyedia layanan kesehatan kepada pasien tidak boleh terganggu. Pada tahap awal bisa dilakukan pendampingan bagi staf yang kesulitan dalam pengisian RMKE oleh staf yang lebih terampil. Selain itu perlu dilakukan pertemuan berkala dan teratur untuk mencari solusi bagi kendala yang dihadapi. Diperlukan juga ahli dan teknisi yang senantiasa siap membantu jika terjadi permasalahan.

Pemimpin rumah sakit bertanggungjawab untuk memotivasi setiap staf agar mengerti pentingnya sistem RMKE dan keuntungan yang bisa dicapai dengan sistem ini. Perlu pengawasan untuk perjalanan sistem RMKE ini. Audit berkala dilakukan untuk memastikan tidak ada penyalahgunaan dan RMKE berjalan sebagaimana mestinya.

\section{KESIMPULAN}

RMKE telah mengubah tatacara layanan kesehatan konvensional, hubungan dokter pasien, dan pemanfaatan informasi/data kesehatan. Tiga hal yang penting diperhatikan terkait penerapan rekam medis elektronik dengan etika kedokteran adalah privacy, confidentiality, dan security. Penyedia layanan kesehatan perlu membuat sistem penerapan RMKE secara lengkap dan dilakukan sosialisasi yang baik. Perlu dukungan penuh seluruh pihak yang terkait dengan pelaksanaan RMKE agar mudah ditangani jika terjadi masalah. RMKE diharapkan akan membantu menciptakan layanan kesehatan yang berorientasi pada kebutuhan pasien, efektif, efisien, dan bermutu. 


\section{KONFLIK KEPENTINGAN}

Penulis tidak memiliki konflik kepentingan dalam penulisan artikel ini.

\section{REFERENSI}

1. Garret P, Seidman J. EMR vs EHR - What is the Difference? | Health IT Buzz [Internet]. Healthit.gov. 2011 [cited 12 July 2019]. Available from: https://www.healthit.gov/ buzz-blog/electronic-health-and-medicalrecords/emr-vs-ehr-difference

2. Li P, Xie C, Pollard T, Johnson A, Cao D, $\mathrm{Kang} \mathrm{H}$ et al. Promoting Secondary Analysis of Electronic Medical Records in China: Summary of the PLAGH-MIT Critical Data Conference and Health Datathon. JMIR Medical Informatics [Internet]. 2017 [cited 12 July 2019];5(4):e43. Available from: https://medinform.jmir.org/2017/4/PDF

3. Dismantling the NHS National Programme for IT [Internet]. GOV.UK. 2011 [cited 12 July 2019]. Available from: https://www. gov.uk/government/news/dismantling-thenhs-national-programme-for-it

4. Saniotis A. Changing ethics in medical practice: a Thai perspective. Indian Journal of Medical Ethics [Internet]. 2007 [cited 12 July 2019];(1). Available from: https://www. researchgate.net/publication/51404984_ Changing_ethics_in_medical_practice_a_ Thai_perspective

5. Electronic Health Records: Types \& Components [Internet]. Study.com. 2019 [cited 12 July 2019]. Available from: https:// study.com/academy/lesson/electronichealth-records-types-components.html

6. Indradi R. Enaknya Rekam Medis Elektronik (RME), Tinggal Klik-Klik Saja, Informasi Langsung Tersedia! - Tribun Jateng [Internet]. Tribun Jateng. 2019 [cited 12 July 2019]. Available from: https://jateng. tribunnews.com/2019/03/27/enaknyarekam-medis-elektronik-rme-tinggal-klikklik-saja-informasi-langsung-tersedia
7. Peraturan Menteri Kesehatan Republik Indonesia Nomor 36 Tahun 2012 Tentang Rahasia Kedokteran

8. Federation of State Medical Board. Report of the Committee on Ethics and Professionalism in the Adoption and Use of Electronic Health Records. 2014; amerika serikat. 